\title{
ATIVIDADE DE FOSFATASES EM GRAMÍNEAS FORRAGEIRAS EM RESPOSTA À DISPONIBILIDADE DE FÓSFORO NO SOLO E À ALTURA DE CORTE DAS PLANTAS ${ }^{(1)}$
}

\author{
Flancer Novais Nunes ${ }^{(2)}$, Reinaldo Bertola Cantarutti ${ }^{(3)}$, Roberto Ferreira \\ Novais ${ }^{(3)}$, Ivo Ribeiro da Silva ${ }^{(3)}$, Marcos Rogério Tótola ${ }^{(4)} \&$ Bruno Neves \\ Ribeiro $^{(5)}$
}

RESUMO

A eficiência de utilização de um nutriente, expressa pela relação entre a biomassa produzida e a quantidade absorvida, é uma importante característica adaptativa das plantas, particularmente daquelas cultivadas em solos com baixa disponibilidade desse nutriente. Maior eficiência de utilização de P (EUP) é conferida pela maior taxa de remobilização de $P$, que consiste na translocação desse nutriente para regiões de maior demanda metabólica na planta. Maiores taxas de remobilização têm sido associadas a maiores atividades das enzimas: fosfatase ácida (APase) e ribonuclease (RNase). Neste trabalho, avaliou-se a atividade dessas enzimas em plantas de Brachiaria decumbens, pouco exigente, $\mathrm{e}$ de Panicum maximum cv. Tanzânia, mais exigente em $P$, cultivadas em solos que receberam diferentes doses desse nutriente e submetidas a diferentes alturas de corte. $O$ ensaio foi realizado em casa de vegetação, utilizando amostra do horizonte B de um Latossolo Vermelho-Amarelo argiloso. Os tratamentos resultaram da combinação fatorial das duas gramíneas, das doses de 100,200 e $500 \mathrm{mg} \mathrm{dm}^{-3} \mathrm{de} P$ e das três alturas de corte: sem corte e corte a 15 e $30 \mathrm{~cm}$ a partir da superfície do solo para Brachiaria; e sem corte e corte a 20 e $40 \mathrm{~cm}$ para Panicum. As unidades experimentais consistiram de vasos com $10 \mathrm{dm}^{3}$ de solo, com 10 plantas. Os

\footnotetext{
(1) Recebido para publicação em novembro de 2007 e aprovado em julho de 2008.

${ }^{(2)}$ Doutorando em Solos e Nutrição de Plantas pelo Departamento de Solos, Universidade Federal de Viçosa - UFV. Avenida P.H. Rolfs s/n., CEP 36571-000 Viçosa (MG). E-mail: flancernovais@yahoo.com.br

(3) Professor do Departamento de Solos, UFV. E-mails: cantarutti@ufv.br; rfnovais@ufv.br; ivosilva@ufv.br

(4) Professor do Departamento de Microbiologia, UFV. E-mail: totola@ufv.br

${ }^{(5)}$ Mestrando em Solos e Nutrição de Plantas pelo Departamento de Solos, UFV.
} 
resultados indicaram que não houve diferença significativa na produção de biomassa das duas gramíneas, mas a adição de $\mathbf{P}$ propiciou maior produção e maior teor desse nutriente na parte aérea de ambas. As plantas submetidas a cortes mais severos apresentaram menor produção e maiores teores de $\mathrm{P}$ na parte aérea. Ocorreu efeito negativo das doses de $\mathrm{P}$ na atividade da APase e da RNase nas duas forrageiras. As plantas cultivadas com a menor dose de $\mathbf{P}$ apresentaram maior atividade dessas enzimas e maior EUP. A atividade de ambas as fosfatases decresceu com a idade das plantas. No tratamento com o corte mais intenso, independentemente da dose de $\mathbf{P}$, tanto Brachiaria quanto Panicum apresentaram menor EUP. Isso ocorreu associado à maior atividade das enzimas APase e RNase, indicando que outros mecanismos relacionados com a adaptação das plantas a baixas disponibilidades de $\mathbf{P}$ podem estar envolvidos.

Termos de indexação: fosfo-hidrolases, ciclagem interna, Brachiaria decumbens, Panicum maximum, eficiência de utilização, eficiência de aquisição.

\title{
SUMMARY: PHOSPHATASE ACTIVITY IN FORAGE GRASSES AS INFLUENCED BY SOIL PHOSPHORUS AVAILABILITY AND PLANT CUTTING HEIGHT
}

\begin{abstract}
The nutrient use efficiency, expressed by the ratio between the produced biomass and nutrient content, is an important adaptive characteristic of plants, particularly of those cultivated in low-fertility soils. A high P-use efficiency (PUE) is conferred by high $P$ remobilization rates, i.e., $P$ transport to regions of greater metabolic demand in the plant. High P remobilization rates have been associated with high acid phosphatase (APase) and ribonuclease (RNase) enzyme activities. In our study, we evaluated the activity of these enzymes in Brachiaria decumbens, with a low, and Panicum maximum cv Tanzânia, with a high $P$ demand, cultivated in soil treated with different $P$ rates and cut at different heights. The experiment was carried out in a greenhouse, using B-horizon samples of a clayey Yellow-Red Latosol. The treatments consisted of a factorial combination of two grasses, three Prates (100, 200 and $\left.500 \mathrm{mg} \mathrm{dm}^{-3}\right)$ and three cutting heights: no cutting, 15 and $30 \mathrm{~cm}$ above the soil surface for Brachiaria, and no cutting, 20 and $40 \mathrm{~cm}$ for Panicum. The experimental units consisted of pots with $10 \mathrm{dm}^{3}$ soil, with 10 plants each. Results indicated that there was no significant difference between biomass production of the two grasses, but the $P$ application resulted in a higher biomass yield and $P$ shoot concentration. The biomass production of plants cut at a lower height was smaller and P concentrations in shoots were higher. A significant effect of $P$ rates on the APase and the RNase activities was observed in both forages. In plants grown at the lowest $P$ rate enzyme activities and PUE were the highest. The activity of both phosphatases decreased with plant aging. In the treatment with the lowest cutting height, the PUE in both Brachiaria and Panicum plants was lower, independent of the P rate. At the same time, a higher APase and RNase activity was observed, indicating that other mechanisms may be involved in the plant adaptation to low $P$ availability.
\end{abstract}

Index terms: phosphohydrolases, remobilization, Brachiaria decumbens, Panicum maximum, use efficiency, acquisition efficiency.

\section{INTRODUÇÃO}

Embora o teor de $\mathrm{P}$ total nos solos tropicais possa ser relativamente alto, sua concentração na solução é baixa, geralmente menor que $0,05 \mathrm{mg} \mathrm{L}^{-1}$ (Novais \& Smyth, 1999), em razão da adsorção desse elemento pelos oxihidróxidos de $\mathrm{Fe}$ e $\mathrm{Al}$, principais constituintes da fração argila da maioria desses solos. Assim, a baixa disponibilidade de $\mathrm{P}$ é um dos fatores limitantes ao desenvolvimento e crescimento das plantas.

A adaptação das plantas à baixa disponibilidade de $\mathrm{P}$ no solo é favorecida por mecanismos que aumentam a eficiência de sua aquisição e utilização. Estudos recentes sobre mecanismos de aquisição de $\mathrm{P}$ 
indicam que plantas cultivadas em baixa disponibilidade desse nutriente apresentaram maior síntese radicular de ácidos orgânicos de baixo peso molecular (Narang et al., 2000; Vance et al., 2003; Dong et al., 2004; Nuruzzaman et al., 2006). Shen et al. (2002) verificaram maior exsudação radicular de citrato, fumarato e acetato por plantas de feijão submetidas à deficiência de P. Esses autores constataram que a exsudação de ácidos orgânicos favoreceu a disponibilização e a aquisição de $\mathrm{P}$ por plantas cultivadas em areia enriquecida com $\mathrm{P}-\mathrm{Al}$ e P-Fe.

O fluxo difusivo, que é o mecanismo de transporte predominante de $\mathrm{P}$ no solo, limita seu suprimento às plantas, que elas compensam com aumento da superfície do sistema radicular. Desse modo, mudanças na arquitetura do sistema radicular contribuem para maior aquisição de $\mathrm{P}$ (Vance et al., 2003). A maior relação entre a biomassa da raiz e a da parte aérea é resposta da planta à baixa disponibilidade de $\mathrm{P}$, o que proporciona maior superfície de absorção em relação à biomassa total, favorecendo a aquisição desse nutriente (Narang et al., 2000; Gahoonia \& Nielsen, 2003; Watt \& Evans, 2003; Wissuwa, 2003).

Alterações bioquímicas nas plantas em resposta à baixa disponibilidade de $\mathrm{P}$ no solo, como maior atividade da fosfatase ácida (APase) e da ribonuclease (RNase), também têm sido constatadas (Bosse \& Köck, 1998; Yadav \& Tarafdar, 2001; Yun \& Kaeppler, 2001). As fosfatases estão associadas à remobilização de $\mathrm{P}$ nas plantas. Assim, maior atividade dessas enzimas tem sido associada a baixos teores celulares de $\mathrm{Pi}$ (Richardson et al., 2000; Baldwin, et al., 2001; Bozzo et al., 2006). Além disso, os teores de ATP e de ácidos nucléicos são significativamente reduzidos em plantas deficientes em P, como estratégia para manter o teor de $\mathrm{Pi}$ citoplasmático adequado à manutenção do metabolismo (Raghothama, 1999).

Em algumas espécies de plantas tem sido observado aumento na atividade de fosfatases nas raízes e sua exsudação em resposta à deficiência de $\mathrm{P}$, evidenciando sua importância para a nutrição das plantas (Chen et al., 2003; Richardson et al., 2005; Nuruzzaman et al., 2006). Richardson et al. (2000) observaram que plantas de trigo cultivadas em meio nutritivo estéril foram capazes de utilizar $\mathrm{P}$ de fontes orgânicas, como: ácido fosfoglicérico, adenosina monofosfato, ácido ribonucléico e glucose 1-fosfato. Observaram, ainda, que a liberação de $\mathrm{P}$ dessas fontes orgânicas por fosfatases foi maior do que o requerimento desse nutriente pelas plantas. A elevada atividade extracelular de fosfatases em relação à atividade intracelular sugere que a membrana plasmática é permeável a elas (Yadav \& Tarafdar, 2003), ou que existem transportadores específicos para essas enzimas (Raghothama, 1999).

A elevada atividade das fosfatases nos tecidos vegetais tem sido utilizada como indicadora da deficiência de P nas plantas (Duff et al., 1994). Observa-se correlação negativa entre a atividade das fosfatases e os teores foliares de P (Bosse \& Köck, 1998; Nanamori et al., 2004), o que possibilita associar sua maior atividade a condições de baixa disponibilidade desse nutriente. Por outro lado, Yan et al. (2001) observaram maior atividade da APase em um cultivar de feijão com menor eficiência de utilização de P (EUP), indicando que maior atividade desta enzima pode não estar relacionada com a adaptação das plantas à baixa disponibilidade de P. Dessa forma, ainda há controvérsias a respeito do papel das fosfatases: elas são indicadoras da deficiência de $\mathrm{P}$ ou realmente determinam maiores valores de EUP (Yan et al., 2001).

Bosse \& Köck (1998) cultivaram plântulas de tomate em solução sem $\mathrm{P}$ e observaram que as atividades da APase e da RNase foram substancialmente reduzidas nas plântulas transferidas para a solução com $\mathrm{P}$, comparadas àquelas que continuaram na sua ausência, indicando que há uma degradação ou desativação das fosfatases quando o teor de P na planta retorna em nível satisfatório. Confirmando tal relação, Baldwin et al. (2001) verificaram que o gene LePS2, que controla a síntese de APase, expressouse rapidamente em plantas de tomate e em células cultivadas em meio de cultura sem $\mathrm{P}$ e sua repressão foi induzida pela presença desse nutriente. Isso indica que os teores de $\mathrm{P}$ na planta sinalizam o controle genético da síntese ou a desativação das fosfatases.

Para aumentar a EUP, as plantas desenvolveram mecanismos que estão associados à redução do requerimento de P (Halsted \& Lynch, 1996), conferida por uma remobilização mais eficiente, contribuindo, assim, para adaptação a condições nutricionais limitantes (Yan et al., 2001). Dessa forma, é razoável assumir que as fosfatases estão envolvidas na remobilização de $\mathrm{P}$ dos tecidos velhos para os jovens. Estudando a ciclagem interna de $\mathrm{P}$, Nanamori et al. (2004) observaram que plantas de arroz e, principalmente, de Brachiaria cultivadas em solução nutritiva sem $\mathrm{P}$ apresentaram maior atividade das enzimas APase e RNase do que plantas cultivadas em solução sem restrição no suprimento de $P$. Concluíram, ainda, que a atividade dessas enzimas estava associada à remobilização de $\mathrm{P}$ nas plantas. De modo semelhante, Bosse \& Köck (1998) já haviam observado que a elevada atividade de fosfatases na raiz, e não no meio de crescimento, estava associada à remobilização e não à aquisição de formas orgânicas de P. Dessa forma, especula-se que a elevada ciclagem interna de $\mathrm{P}$ contribui para a adaptação das forrageiras tropicais a solos com baixa disponibilidade desse nutriente e, conseqüentemente, que se expressa pela maior atividade da APase e RNase na planta.

Este trabalho teve como objetivo avaliar o efeito da disponibilidade de $\mathrm{P}$ no solo e de alturas de corte das plantas sobre a atividade da APase e da RNase em Brachiaria decumbens e Panicum maximum cv. Tanzânia. 


\section{MATERIAL E MÉTODOS}

O experimento foi conduzido em casa de vegetação, utilizando-se amostra do horizonte B de um Latossolo Vermelho-Amarelo distroférrico típico argiloso (670 $\mathrm{g} \mathrm{kg}^{-1}$ de argila), cuja análise química apresentou: pH em água de 4,5; teores de $\mathrm{P}$ e K pelo Mehlich-1 de a 0,4 e $8 \mathrm{mg} \mathrm{dm}^{-3}$, respectivamente; e saturação por bases de $4 \%$. As espécies forageiras utilizadas foram Brachiaria decumbens e Panicum maximum cv. Tanzânia, consideradas de menor e maior requerimento em $\mathrm{P}$, respectivamente.

Os tratamentos resultaram da combinação fatorial entre as duas espécies forrageiras, as doses de 100, 200 e $500 \mathrm{mg} \mathrm{dm}^{-3}$ de $\mathrm{P}$ e três alturas de corte das plantas: sem corte e corte a 15 e a $30 \mathrm{~cm}$ de altura a partir da superfície do solo, para Brachiaria, e sem corte e cortes a 20 e a $40 \mathrm{~cm}$ para o Panicum. As forrageiras foram mantidas nas respectivas alturas de corte por meio de podas a cada cinco dias. O delineamento experimental foi inteiramente casualizado com três repetições. As unidades experimentais consistiram de vasos com $10 \mathrm{dm}^{3} \mathrm{de}$ solo passado em peneira de $4 \mathrm{~mm}$ de malha, com 10 plantas. Sessenta dias antes do plantio, o solo de cada unidade experimental recebeu calagem para neutralizar o $\mathrm{Al}^{3+}$ e elevar os teores de $\mathrm{Ca}^{2+}+\mathrm{Mg}^{2+}$ a $2 \mathrm{cmol}_{\mathrm{c}} \mathrm{dm}^{-3}$ (CFSEMG, 1999), utilizando-se uma mistura de $\mathrm{CaCO}_{3}$ e $\mathrm{MgCO}_{3}$ na relação molar de 4:1. Após a aplicação do corretivo, a umidade do solo foi elevada a $80 \%$ da capacidade de campo e mantida durante 30 dias por meio de irrigações com água deionizada; o volume de água adicionado foi determinado após pesagem. No final desse período, o solo foi seco e passado novamente em peneira de $4 \mathrm{~mm}$. Em seguida, foram aplicadas as três doses de $\mathrm{P}$ $\left(\mathrm{KH}_{2} \mathrm{PO}_{4}\right)$, juntamente com doses de $\mathrm{KCl}$ suficientes para igualar as doses de $\mathrm{K}$ a $630 \mathrm{mg} \mathrm{dm}^{-3}$. Os fertilizantes foram homogeneizados com todo o volume de solo de cada unidade experimental, e a umidade, mantida em $80 \%$ da capacidade de campo durante 30 dias. A análise de amostras do solo coletadas após a adição dos tratamentos revelaram teores de $\mathrm{P}$ de 9,4, 31,3 e 329,0 mg dm ${ }^{-3}$ pelo Mehlich-1, para as doses de 100,200 e $500 \mathrm{mg} \mathrm{dm}^{-3}$ de $\mathrm{P}$, respectivamente. No fim desse período, 10 plântulas, com duas ou três folhas, de cada espécie, crescidas em areia, foram transplantadas nos respectivos vasos. Uma semana depois, aplicaram-se $50 \mathrm{~mL}$ de uma solução que supriu $25 \mathrm{mg} \mathrm{dm}^{-3}$ de $\mathrm{N}\left[\left(\mathrm{NH}_{4}\right)_{2} \mathrm{SO}_{4}\right]$ e 4,$0 ; 1,4 ; 1,6 ; 3,7 ; 0,95$ e $0,15 \mathrm{mg} \mathrm{dm}^{-3} \mathrm{de} \mathrm{Zn}, \mathrm{Cu}, \mathrm{Fe}, \mathrm{Mn}$ (sulfatos), $\mathrm{B}\left(\mathrm{H}_{3} \mathrm{BO}_{3}\right)$ e $\mathrm{Mo}\left(\mathrm{Na}_{2} \mathrm{MoO}_{4}\right)$, respectivamente. Até 60 dias após o transplantio foram aplicados, semanalmente, $25 \mathrm{mg} \mathrm{dm}^{-3}$ de $\mathrm{N}\left[\left(\mathrm{NH}_{4}\right)_{2} \mathrm{SO}_{4}\right]$. Posteriormente, foram aplicadas seis doses, uma por semana, de $50 \mathrm{mg} \mathrm{dm}^{-3}$ de $\mathrm{N}$ (solução de $\mathrm{NH}_{4} \mathrm{NO}_{3}$ ).

Aos 60 dias após o transplantio, fez-se o primeiro corte das forrageiras. Nessa ocasião, foram selecionados e identificados 10 perfilhos (um por planta) no mesmo estádio de desenvolvimento em cada vaso. O mesmo procedimento foi realizado nas plantas mantidas sem corte. Nesse momento, foram coletadas duas plantas. Em cada planta, no perfilho previamente selecionado, obteve-se um segmento de $10 \mathrm{~cm}$ da parte intermediária da lâmina foliar, um segmento de $2 \mathrm{~cm}$ da base do caule (coleto) e, aproximadamente, $0,5 \mathrm{~g}$ de raízes (peso seco). Os materiais dos dois perfilhos foram devidamente lavados, reunidos em uma amostra composta e imediatamente congelados $\left(-80^{\circ} \mathrm{C}\right)$, para posterior dosagem da atividade da APase e RNase. Posteriormente, seguindo este mesmo procedimento, duas plantas foram coletadas aos sete, 15,30 e 45 dias. O material coletado foi seco a $70^{\circ} \mathrm{C}$ por $72 \mathrm{~h}$, pesado e juntado ao material vegetal das podas de manutenção da altura para posterior análise.

As enzimas RNase e APase foram extraídas macerando-se aproximadamente $0,5 \mathrm{~g}$ do material vegetal em um almofariz previamente resfriado, com $2 \mathrm{~mL}$ de acetato de sódio $100 \mathrm{mmol} \mathrm{L}^{-1}$ (pH 5,6). O extrato foi centrifugado a $17.000 \mathrm{ga} 4^{\circ} \mathrm{C}$, por $20 \mathrm{~min}$, e o sobrenadante foi congelado a $-80{ }^{\circ} \mathrm{C}$. Posteriormente, determinou-se no sobrenadante o conteúdo de proteína total, tomando como padrão a albumina de soro bovino (Lowry et al., 1951).

A atividade da RNase foi determinada conforme método sugerido por Abel \& Glund (1986). Para isso, a uma alíquota de $100 \mu \mathrm{L}$ do sobrenadante foram adicionados $50 \mu \mathrm{L}$ de acetato de sódio $50 \mathrm{mmol} \mathrm{L}^{-1}$ pH 5,6, contendo $250 \mu \mathrm{g}$ de RNA como substrato, incubado por $10 \mathrm{~min}$ a $37^{\circ} \mathrm{C}$. Em seguida, adicionouse $1,35 \mathrm{~mL}$ de uma solução com $500 \mathrm{~mL} \mathrm{~L}^{-1}$ de etanol, $48 \mathrm{mmol} \mathrm{L}^{-1}$ de acetato de sódio $\mathrm{pH} 5,6,12,5 \mathrm{mmol} \mathrm{L}^{-1}$ de acetato de magnésio e $0,85 \mathrm{mmol}$ de nitrato de lantano, para precipitar o RNA remanescente. O tempo de reação foi de $45 \mathrm{~min}$ a $-20^{\circ} \mathrm{C}$. A mistura foi centrifugada a $23.000 \mathrm{~g}$ por $5 \mathrm{~min}$ e mediu-se a absorbância do sobrenadante a $260 \mathrm{~nm}$ (Espectrofotômetro Smart Spec 3000, Bio Rad, Inc., USA). Uma unidade enzimática foi definida como a quantidade de enzima no extrato que promoveu acréscimo de uma unidade na absorbância por minuto, por centímetro (Wilson, 1975).

A atividade da APase foi determinada pela incubação por $5 \mathrm{~min}$ a $37^{\circ} \mathrm{C}$ de $500 \mu \mathrm{L}$ do sobrenadante com $200 \mu \mathrm{L}$ do substrato $\left(2 \mathrm{mmol} \mathrm{L}^{-1}\right.$ de p-nitrofenilfosfato dissódico e $150 \mathrm{mmol} \mathrm{L}^{-1}$ de acetato de sódio pH 5,6). Após a incubação, a reação foi interrompida pela adição de $300 \mu \mathrm{L}$ de solução saturada de $\mathrm{Na}_{2} \mathrm{CO}_{3}$ e mediu-se a absorbância a $400 \mathrm{~nm}$, que é proporcional à quantidade de $\mathrm{p}$ nitrofenol hidrolisada. Uma unidade enzimática foi definida como a quantidade de enzima no extrato capaz de hidrolisar $1 \mathrm{mmol}$ de $\mathrm{p}$-nitrofenilfosfato por minuto (Ozawa et al., 1995). Os resultados para ambas as enzimas foram expressos em unidade enzimática por miligrama de proteína. 
No material vegetal seco moído foram determinados os teores de $\mathrm{N}$ por meio da destilação Kjeldahl, e os de $\mathrm{P}$, após digestão nítrico-perclórica $(4: 1 \mathrm{v} / \mathrm{v})$, por colorimetria (Muphy \& Riley, 1962). A partir da massa e do teor de $\mathrm{P}$, foi estimado o conteúdo desse nutriente na biomassa vegetal, e calculou-se a EUP conforme Siddiqi \& Glass (1981):

\section{$\mathrm{EUP}=$ massa de matéria seca²/conteúdo de $\mathrm{P}$}

Os dados de massa de matéria seca, teores foliares de $\mathrm{N}$ e $\mathrm{P}$, relação N/P, EUP e as quantidades de $\mathrm{P}$ e $\mathrm{N}$ absorvidas por vaso foram submetidos à análise de variância e teste de médias. A atividade da APase e da RNase foi interpretada por meio das estatísticas descritivas: média e erro-padrão. $\mathrm{O}$ efeito das doses de $\mathrm{P}$ sobre as atividades das fosfatases foi avaliado utilizando-se o material vegetal coletado 60 dias após o transplantio. As análises estatísticas foram realizadas com auxílio do Sistema de Análises Estatísticas e Genéticas (Euclides, 1983).

\section{RESULTADOS E DISCUSSÃO}

Houve efeito positivo das maiores doses de $\mathrm{P}$ sobre a produção das forrageiras independentemente da altura de corte (Quadro 1). Os incrementos na produção de matéria seca entre a menor e a maior dose de $\mathrm{P}$ foram, em média, de 120 e $64 \%$ para Brachiaria e Panicum, respectivamente. Houve diferença significativa na produção de biomassa pelas forrageiras, em todas as doses de P, entre os tratamentos sem corte e com corte mais intenso. No tratamento sem corte, Brachiaria e Panicum apresentaram, em média, produção de matéria seca 67 e $64 \%$ maior do que das plantas submetidas à menor altura de corte. Panicum apresentou maior produção média nas diferentes alturas de corte que Brachiaria, exceto na maior dose de $\mathrm{P}(\mathrm{p}>0,05)$. Com comportamento semelhante, a maior eficiência de utilização de P (EUP) do Panicum foi altamente significativa, exceto na maior dose desse nutriente. A maior EUP para o Panicum não era esperada, pois as espécies do gênero Brachiaria apresentam menor requerimento desse elemento e elevada EUP (Rao et al., 1995).

Os teores de P nas plantas submetidas ao corte mais intenso foram maiores do que nas plantas que não foram cortadas ( $p<0,001$; Quadro 1). Nas plantas sem o corte, o teor médio de $\mathrm{P}$, para todas as doses, foi 1,51 vez menor para Brachiaria e 1,84 para Panicum que o teor das plantas submetidas ao corte mais baixo. Isso pode estar relacionado com a significativa redução na EUP dessas gramíneas com a intensificação do corte. O maior teor de $\mathrm{P}$ nas plantas sob os cortes mais severos deve-se, em parte, à contribuição de tecidos mais jovens, ricos em $\mathrm{P}$, coletados a cada corte e a possibilidade de a remoção parcial da parte aérea promover menor relação parte aérea/raiz. Uma menor relação parte aérea/raiz tem sido apontada como mecanismo importante para maior eficiência de aquisição de P (Raghothama, 1999; Narang et al., 2000; Watt \& Evans, 2003), dada à baixa mobilidade desse nutriente no solo (Barber, 1995; Novais \& Smyth, 1999).

O teor de N na parte aérea (Quadro 1) foi, de modo geral, menor nas plantas com a maior dose de $\mathrm{P}$ e nas plantas sem corte $(p<0,001)$, o que se justifica pela diluição do $\mathrm{N}$ com a maior produção de biomassa. Contrariamente ao teor de $\mathrm{N}$, observou-se maior quantidade de $\mathrm{N}$ absorvido nas plantas com as maiores doses de $\mathrm{P}$, sugerindo que, quanto menor a limitação por P, maior é a absorção de N (Rufty Jr. et al., 1990). De modo geral, limitações à absorção de $\mathrm{N}$ por plantas deficientes em $\mathrm{P}$ podem estar relacionadas a efeitos enérgicos. Nesse caso, o menor teor de ATP celular pode reduzir a assimilação e o transporte desse nutriente através da membrana (Rufty Jr. et al., 1993).

Para as duas gramíneas houve efeito negativo das doses de $\mathrm{P}$ sobre a atividade das enzimas APase e RNase (Figura 1). A atividade da APase foi, em média, 2,78 e 2,54 vezes maior nas plantas com a menor dose de $\mathrm{P}$, na Brachiaria e no Panicum, respectivamente (Figura 1a,b). Para a atividade da RNase, essa mesma relação foi de 2,82 e 2,74 vezes (Figura 1c,d). A maior atividade dessas enzimas tem sido associada à maior remobilização de $\mathrm{P}$, conferindo às plantas maior EUP quando cultivadas em limitada disponibilidade deste nutriente. Segundo Nanamori et al. (2004), em condições de baixa disponibilidade de $\mathrm{P}$, plantas de Brachiaria e arroz apresentaram maior atividade dessas fosfoidrolases, que, provavelmente, estão associadas a maiores taxas de remobilização e utilização mais eficiente desse nutriente. Assim, em condições de deficiência, as plantas utilizam mecanismos que ativam a desfosforilação de compostos orgânicos, disponibilizando $\mathrm{P}$ inorgânico para manutenção do metabolismo celular em regiões meristemáticas (Raghothama, 1999; Nanamori et al., 2004). A maior atividade de fosfatases como resposta adaptativa à baixa disponibilidade de $\mathrm{P}$ tem sido observada, também, para outras espécies de plantas (Ozawa et al., 1995; Yun \& Kaeppler, 2001; Bozzo et al., 2006).

Brachiaria apresentou maior teor e conteúdo de $\mathrm{P}$ que Panicum na menor dose desse elemento (Quadro 1), sugerindo maior eficiência de aquisição de $\mathrm{P}$, quando esse nutriente encontra-se em baixa disponibilidade no solo. Isso é suportado pela maior atividade da APase na raiz de Brachiaria cultivada com a menor dose de P (Figura 1b). A maior atividade das fosfatases nas raízes das plantas e sua exsudação para a rizosfera têm sido apontadas como importantes estratégias de aquisição de $\mathrm{P}$, por possibilitarem utilização de formas orgânicas desse nutriente (Gaume et al., 2001; Vance et al., 2003; George et al., 2006). Chen et al. (2003) verificaram que o crescimento de Pinus radiata em solos com diferentes teores de Po foi 
Quadro 1. Produção de biomassa (matéria seca - MS), teores de N e P, eficiência de utilização de P (EUP), relação entre os teores de $\mathrm{N}$ e $\mathrm{P}(\mathrm{N} / \mathrm{P})$ na matéria seca e $\mathrm{N}$ e $\mathrm{P}$ absorvido e acumulado na parte aérea (Nab e Pab) por Brachiaria decumbens e Panicum maximum, de acordo com doses de $\mathrm{P}$ e alturas de corte

\begin{tabular}{|c|c|c|c|c|c|c|c|c|}
\hline Dose P & Altura de corte & MS & $\mathbf{N}$ & $\mathbf{P}$ & EUP & $\mathbf{N} / \mathbf{P}$ & Nab & $\mathbf{P a b}$ \\
\hline \multirow[t]{2}{*}{$\mathrm{mg} \mathrm{dm} \mathrm{m}^{-3}$} & $\mathrm{~cm}$ & $\mathrm{~g} /$ vaso & $-\mathrm{d}$ & $\mathrm{g}^{-1}$ & \multicolumn{2}{|l|}{$\mathrm{g}^{2} \mathrm{mg}^{-1}$} & \multicolumn{2}{|c|}{ mg/vaso } \\
\hline & \multicolumn{8}{|c|}{ Brachiaria decumbens } \\
\hline \multirow[t]{3}{*}{100} & $0^{(1)}$ & $128,53 \mathrm{Ac}$ & $1,67 \mathrm{Bb}$ & $0,147 \mathrm{Ca}$ & $680 \mathrm{Aa}$ & $11,37 \mathrm{Ba}$ & $2.140 \mathrm{Ab}$ & $189 \mathrm{Abc}$ \\
\hline & 30 & $78,15 \mathrm{Bc}$ & $2,77 \mathrm{Aa}$ & $0,196 \mathrm{Aab}$ & $510 \mathrm{Bb}$ & $14,18 \mathrm{Aa}$ & $2.159 \mathrm{Ab}$ & $153 \mathrm{Ac}$ \\
\hline & 15 & $69,25 \mathrm{Bc}$ & $2,67 \mathrm{Aa}$ & $0,176 \mathrm{Bb}$ & $568 \mathrm{Bb}$ & $15,20 \mathrm{Aa}$ & $1.840 \mathrm{Ab}$ & $122 \mathrm{Bc}$ \\
\hline Média & & 91,98 & 2,37 & 0,173 & 586 & 13,58 & 2.047 & 155 \\
\hline \multirow[t]{3}{*}{200} & 0 & $195,52 \mathrm{Aa}$ & $1,26 \mathrm{Bbc}$ & $0,108 \mathrm{Bb}$ & $926 \mathrm{Aa}$ & $11,68 \mathrm{Aa}$ & $2.441 \mathrm{Aa}$ & $209 \mathrm{Ab}$ \\
\hline & 30 & $151,36 \mathrm{ABb}$ & $1,79 \mathrm{Ab}$ & $0,166 \mathrm{Ab}$ & $602 \mathrm{Bab}$ & $10,85 \mathrm{Ab}$ & $2.701 \mathrm{Aa}$ & $250 \mathrm{Ab}$ \\
\hline & 15 & $122,32 \mathrm{Bb}$ & $1,95 \mathrm{Ab}$ & $0,176 \mathrm{Ab}$ & $568 \mathrm{Bb}$ & $11,07 \mathrm{Ab}$ & $2.364 \mathrm{Ab}$ & $215 \mathrm{Ab}$ \\
\hline Média & & 156,40 & 1,67 & 0,150 & 698 & 11,20 & 2.502 & 225 \\
\hline \multirow[t]{3}{*}{500} & 0 & $239,87 \mathrm{Aa}$ & $0,99 \mathrm{Bbc}$ & $0,135 \mathrm{Bab}$ & $741 \mathrm{Aa}$ & $7,44 \mathrm{Ac}$ & $2.376 \mathrm{Ba}$ & $323 \mathrm{Ba}$ \\
\hline & 30 & $182,77 \mathrm{Ba}$ & $1,64 \mathrm{Ab}$ & $0,219 \mathrm{Aa}$ & $457 \mathrm{Bc}$ & $7,48 \mathrm{Ac}$ & $2.990 \mathrm{Aa}$ & $401 \mathrm{Aa}$ \\
\hline & 15 & $183,25 \mathrm{Ba}$ & $1,78 \mathrm{Ab}$ & $0,235 \mathrm{Aa}$ & $426 \mathrm{Bc}$ & $7,62 \mathrm{Ac}$ & $3.255 \mathrm{Aa}$ & $431 \mathrm{Aa}$ \\
\hline \multirow[t]{2}{*}{ Média } & & 201,96 & 1,47 & 0,197 & 540 & 7,51 & 2.874 & 385 \\
\hline & \multicolumn{8}{|c|}{ Panicum maximum cv. Tanzânia } \\
\hline \multirow[t]{3}{*}{100} & 0 & $120,01 \mathrm{Ab}$ & $1,73 \mathrm{Ba}$ & $0,066 \mathrm{Bc}$ & $1515 \mathrm{Aa}$ & $26,39 \mathrm{Aa}$ & $2.072 \mathrm{ABa}$ & $79,4 \mathrm{Cc}$ \\
\hline & 40 & $101,23 \mathrm{Ab}$ & $2,18 \mathrm{Aa}$ & $0,143 \mathrm{Ab}$ & $699 \mathrm{Bb}$ & $15,43 \mathrm{Ba}$ & $2.204 \mathrm{Aa}$ & $144,7 \mathrm{Abc}$ \\
\hline & 20 & $82,94 \mathrm{Bb}$ & $2,06 \mathrm{Aa}$ & $0,125 \mathrm{Ab}$ & $800 \mathrm{Ba}$ & $16,72 \mathrm{Ba}$ & $1.715 \mathrm{Bb}$ & $104,8 \mathrm{Bc}$ \\
\hline Média & & 101,39 & 1,99 & 0,111 & 1005 & 19,51 & 1.997 & 109,7 \\
\hline \multirow[t]{3}{*}{200} & 0 & $199,76 \mathrm{Aa}$ & $1,15 \mathrm{Bb}$ & $0,078 \mathrm{Cc}$ & $1282 \mathrm{Aa}$ & $14,70 \mathrm{Aa}$ & $2.281 \mathrm{ABa}$ & $156,2 \mathrm{Ab}$ \\
\hline & 40 & $166,96 \mathrm{Ba}$ & $1,54 \mathrm{Ab}$ & $0,119 \mathrm{Bb}$ & $840 \mathrm{Ba}$ & $13,02 \mathrm{Ab}$ & $2.563 \mathrm{Aa}$ & $197,9 \mathrm{Ab}$ \\
\hline & 20 & $122,62 \mathrm{Cb}$ & $1,69 \mathrm{Ab}$ & $0,167 \mathrm{Ab}$ & $599 \mathrm{Cbc}$ & $10,16 \mathrm{Bb}$ & $2.066 \mathrm{Bab}$ & $205,6 \mathrm{Ab}$ \\
\hline Média & & 163,11 & 1,46 & 0,121 & 907 & 12,63 & 2.303 & 186,6 \\
\hline \multirow[t]{3}{*}{500} & 0 & $207,01 \mathrm{Aa}$ & $1,00 \mathrm{Bb}$ & $0,200 \mathrm{Ca}$ & $500 \mathrm{Ac}$ & $5,01 \mathrm{Ac}$ & $2.069 \mathrm{Ca}$ & $415,4 \mathrm{Aa}$ \\
\hline & 40 & $160,54 \mathrm{Ba}$ & $1,74 \mathrm{Ab}$ & $0,287 \mathrm{Ba}$ & $348 \mathrm{Bc}$ & $6,09 \mathrm{Ac}$ & $2.792 \mathrm{Aa}$ & $459,7 \mathrm{Aa}$ \\
\hline & 20 & $130,45 \mathrm{Ca}$ & $1,74 \mathrm{Ab}$ & $0,335 \mathrm{Aa}$ & $299 \mathrm{Cc}$ & $5,21 \mathrm{Ac}$ & $2.273 \mathrm{Ba}$ & $436,6 \mathrm{Aa}$ \\
\hline Média & & 166,00 & 1,49 & 0,274 & 382 & 5,43 & 2.378 & 437,2 \\
\hline
\end{tabular}

(1) Plantas mantidas com crescimento contínuo sem corte. Para cada dose de P (efeito das alturas de corte), médias seguidas pela mesma letra maiúscula, e para cada corte (efeito das doses de P), médias seguidas pela mesma letra minúscula não diferiram pelo teste de Tukey a $5 \%$.

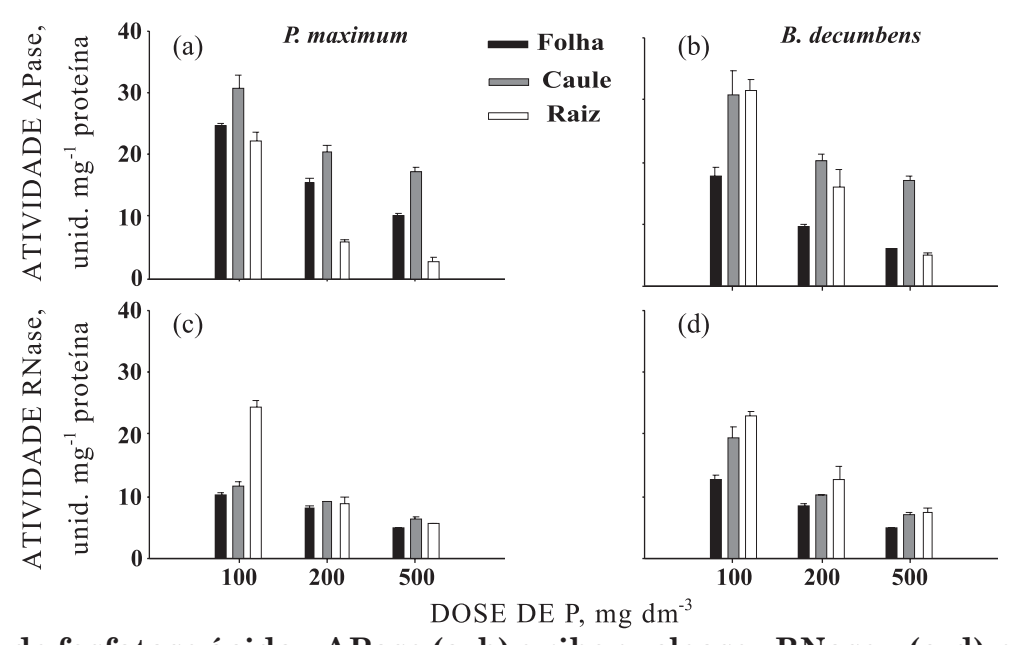

Figura 1. Atividade de fosfatase ácida-APase (a, b) e ribonuclease - RNase - (c, d) na folha, caule e raiz de plantas de Panicum maximum (a,c) e Brachiaria decumbens $(b, d)$ coletadas aos 60 dias após o transplantio, antes do início dos tratamentos com cortes, de acordo com as doses de 100,200 e $500 \mathrm{mg} \mathrm{dm}^{-3} \mathrm{de} \mathrm{P}_{\text {. As }}$ linhas sobre as barras correspondem ao erro-padrão. 
associado à maior capacidade em utilizar formas orgânicas de $\mathrm{P}$, devido à maior síntese de fosfatases, principalmente em solos com baixo teor de $\mathrm{P}$ disponível.

A atividade da APase e principalmente da RNase nas folhas de Brachiaria e Panicum decresceu com a idade das plantas (Figura 2), concordando com a tendência observada por Bosse \& Köck (1998). Esse comportamento relaciona-se, possivelmente, com a redução da demanda de $\mathrm{P}$ com a idade das plantas. Santos et al. (2002), trabalhando com essas mesmas espécies forrageiras, observaram que os níveis críticos de $\mathrm{P}$, tanto na parte aérea da planta quanto no solo, reduziram exponencialmente com a idade das plantas. A maior redução na atividade da RNase com a idade da planta sugere que ela foi mais sensível do que a APase à redução na demanda de $\mathrm{P}$ pelas plantas (Figura 2c,d).

A maior EUP verificada para Panicum, nas menores doses de $\mathrm{P}$, pode estar relacionada com a maior atividade da APase na folha e no caule (Figuras 1a e 2b). A maior atividade da APase nas folhas de Panicum (Figura 2a,b), que provavelmente contribuiu para maior EUP, pode estar indicando que a aquisição de $\mathrm{P}$ não foi tão eficiente quanto a de Brachiaria, com menor disponibilidade de P no solo. Isso é confirmado pela menor atividade da APase nas folhas de Brachiaria, quando cultivada com menor disponibilidade de P (Figura 2b). Dessa forma, é provável que a menor EUP apresentada pela
Brachiaria com a menor dose de $\mathrm{P}$ tenha sido decorrente mais da sua maior eficiência de aquisição de $\mathrm{P}$ do que da sua remobilização, visto que esta apresentou maior quantidade de $\mathrm{P}$ absorvido e menor produção de matéria seca. Segundo Bosse \& Köck (1998), maiores atividades dessa fosfatase em plantas de tomate cultivadas em baixa disponibilidade de $\mathrm{P}$ relacionaram-se com maior remobilização desse nutriente e maior EUP. A maior atividade da APase, associada à remobilização de $\mathrm{P}$ mais elevada, também foi constatada por Duff et al. (1994).

Independentemente da altura de corte, houve menor atividade da APase e RNase no caule e na raiz das duas gramíneas nas maiores doses de P, evidenciando o efeito negativo da adubação fosfatada na atividade das fosfatases (Figuras 3 e 4). Com o aumento da idade também houve redução na atividade dessas fosfatases nas folhas, no caule e nas raízes das duas gramíneas (Figuras 2, 3 e 4), o que pode estar associado à redução na demanda de $\mathrm{P}$ (Santos et al., 2002).

Observou-se que, nas plantas sem corte, a atividade da APase e da RNase decresceu até os 45 dias (Figuras 3 e 4). Por outro lado, nas plantas submetidas à menor altura de corte, constatou-se tendência de elevação na atividade de ambas as fosfatases a partir dos 30 dias após o início dos cortes. Isso sugere aumento na remobilização de $\mathrm{P}$ nas plantas com o estresse causado pelos cortes, mesmo tendo

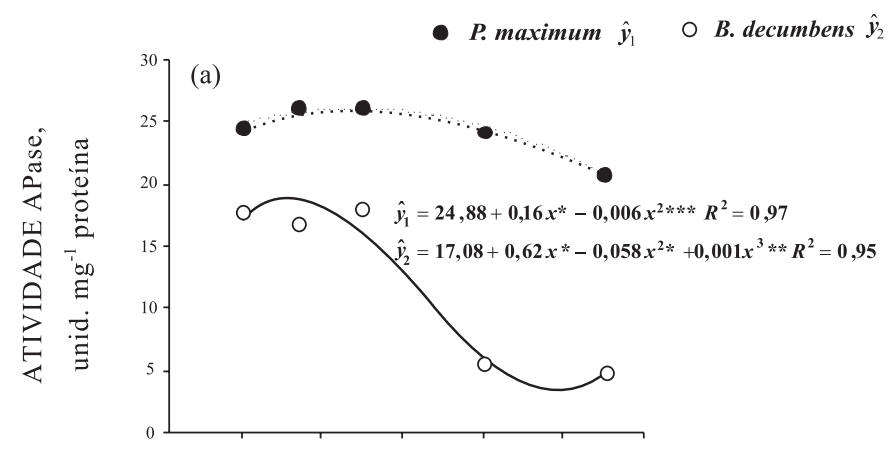

(b)

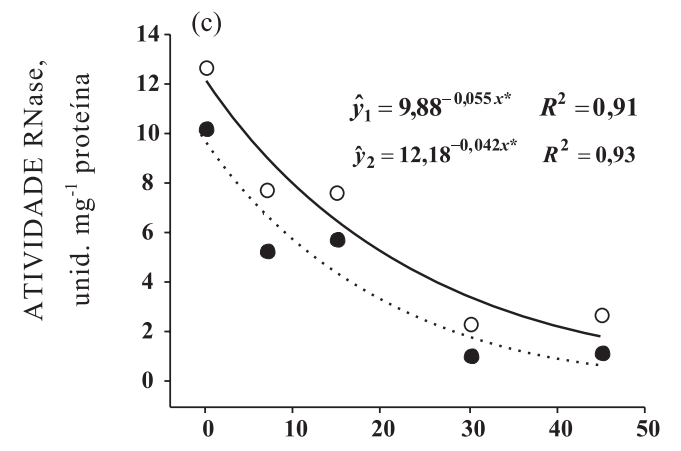

(d)

DIAS APÓS PRIMEIRO CORTE

Figura 2. Atividade da fosfatase ácida - APase (a, b) e da Ribonuclease-RNase (c, d) na folha de Brachiaria decumbens e Panicum maximum para as doses de $100(\mathrm{a}, \mathrm{c})$ e $500 \mathrm{mg} \mathrm{dm}^{-3}(\mathrm{~b}, \mathrm{~d})$ por ocasião do primeiro corte (tempo zero), e até 45 dias após. ***,**,*: significativo a $0,1,1$ e a $5 \%$ pelo teste $F$. 

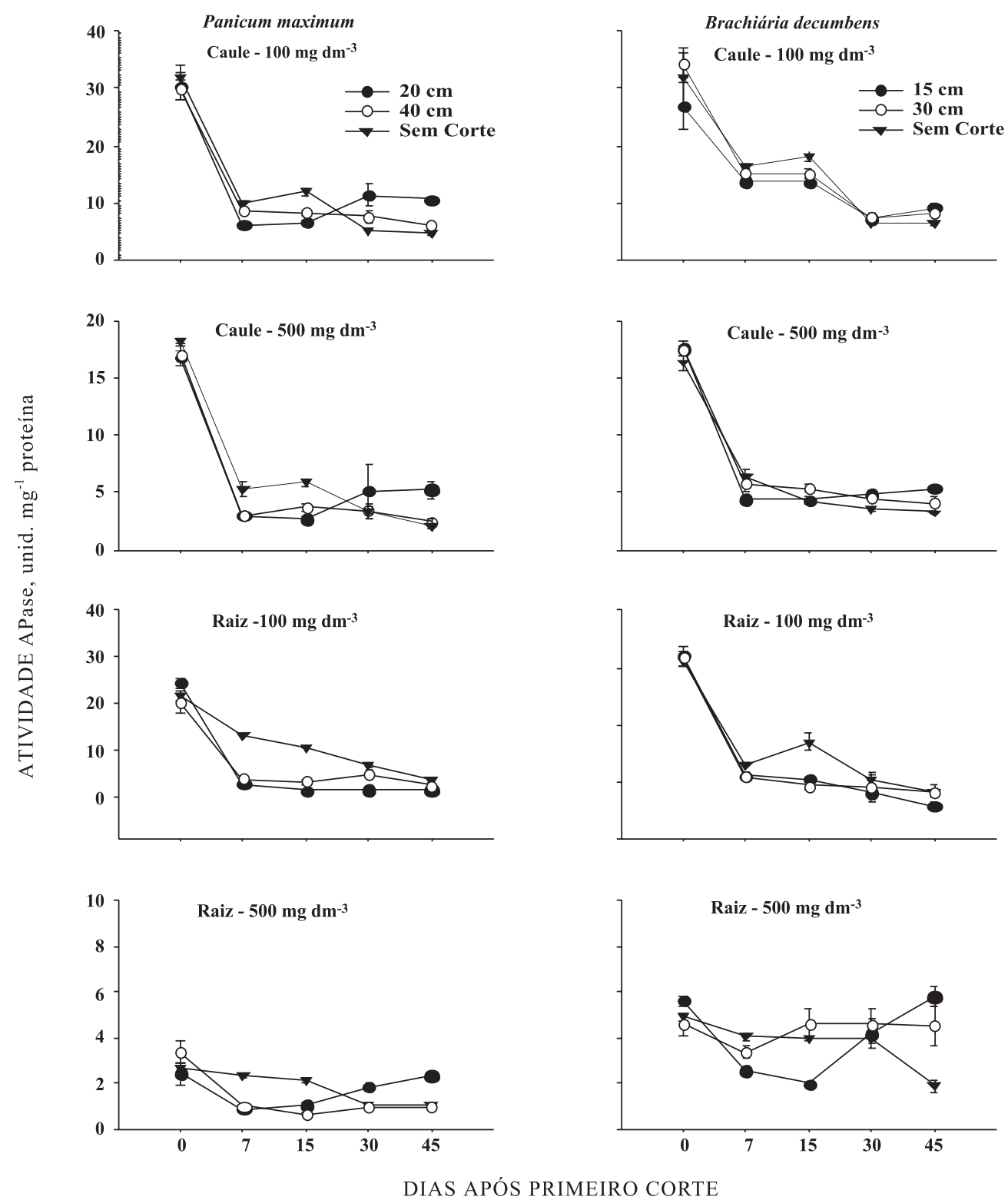

Figura 3. Atividade da fosfatase ácida (APase) no caule e raiz das forrageiras Panicum maximum e Brachiaria decumbens fertilizadas com 100 e $500 \mathrm{mg} \mathrm{dm}^{-3}$ de $\mathrm{P}$ e mantidas sem corte e com duas alturas de corte, em amostras coletadas aos 60 dias após o transplantio das plântulas, quando se realizou o primeiro corte (tempo zero), e depois, aos sete, 15, 30 e 45 dias. As linhas verticais representam os erros-padrão.

apresentado maior capacidade de aquisição de $\mathrm{P}$, conforme já discutido; porém não contribuiu para maior EUP.

As plantas submetidas ao corte mais intenso apresentaram menor eficiência de utilização de $P$, mesmo havendo maior atividade das fosfatases, o que sugere maior remobilização. Visto isso, investigações adicionais sobre o papel dessas enzimas no metabolismo vegetal merecem maior atenção, pois algumas observações indicam que a atividade dessas enzimas pode não conferir às plantas maior tolerância a condições limitantes de P (Yan et al., 2001). Sugerese que outros mecanismos de adaptação a condições limitantes de $\mathrm{P}$ possam estar envolvidos, como maior exsudação de ácidos orgânicos e fosfatases e maior crescimento do sistema radicular.

\section{CONCLUSÕES}

1. As maiores doses de $\mathrm{P}$ promoveram maiores produções de biomassa e maiores teores desse nutriente nas plantas, sendo a Brachiaria decumbens mais responsiva ao $\mathrm{P}$ do que o Panicum maximum cv. Tanzânia. 

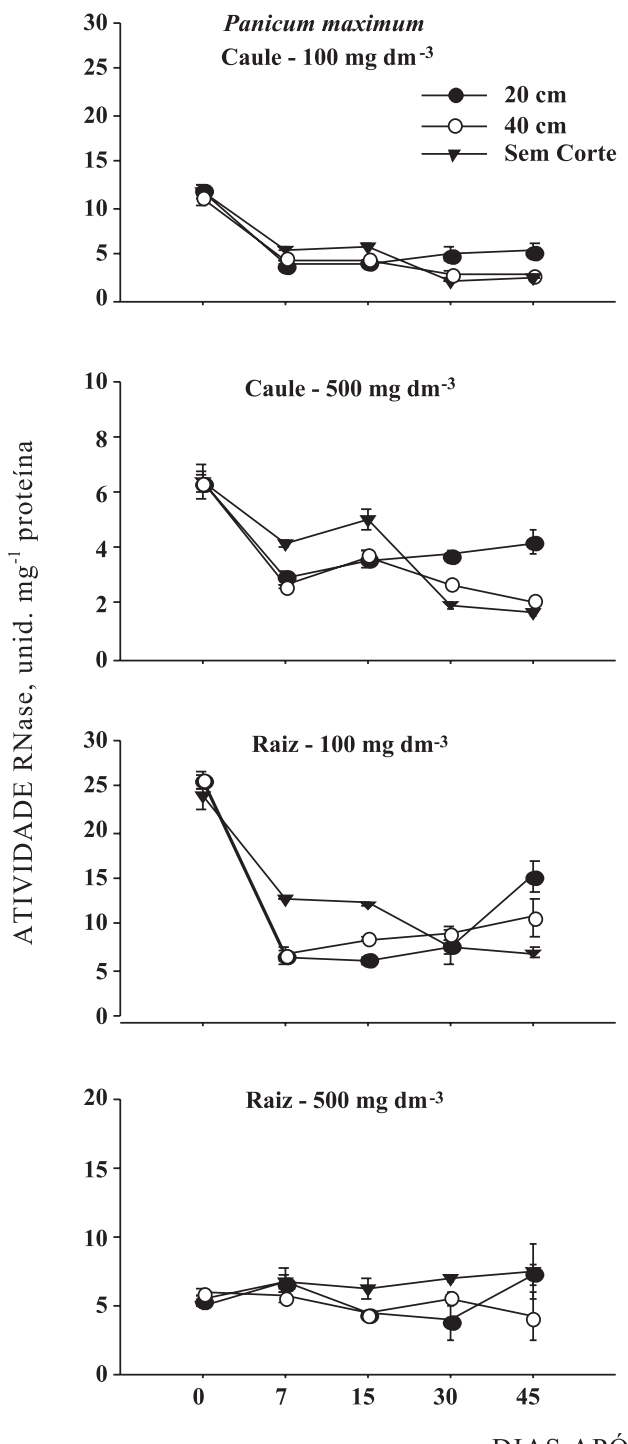
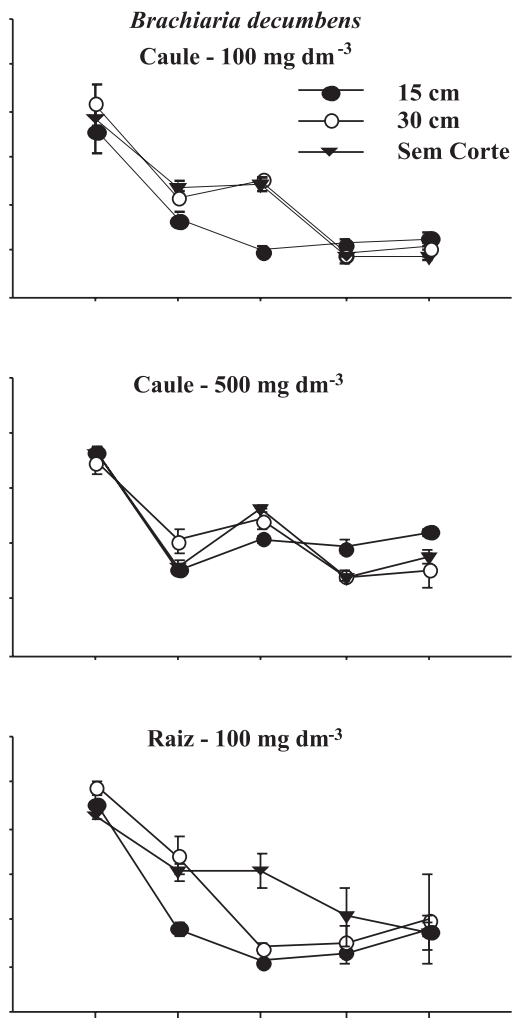

Raiz - 500 mg dm -3 $^{3}$

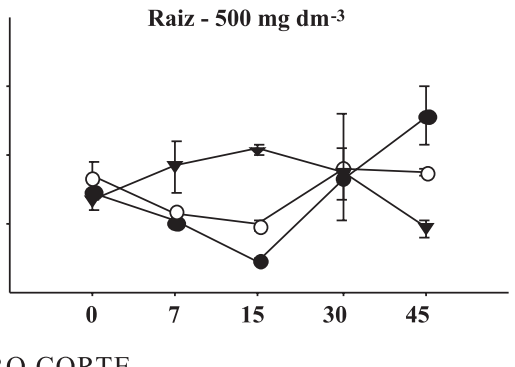

Figura 4. Atividade da ribonuclease (RNase) no caule e raiz das forrageiras Panicum maximum e Brachiaria decumbens fertilizadas com 100 e $500 \mathrm{mg} \mathrm{dm}^{-3}$ de $\mathrm{P}$ e mantidas sem corte e com duas alturas de corte, em amostras coletadas aos 60 dias após o transplantio das plântulas, quando se realizou o primeiro corte (tempo zero), e depois, aos sete, 15, 30 e 45 dias. As linhas verticais representam os erros-padrão.

2. Plantas submetidas a cortes mais intensos apresentaram menor produção de biomassa e maiores teores de P na parte aérea.

3. As plantas cultivadas com baixa disponibilidade de $\mathrm{P}$ mostraram menor eficiência de utilização de $\mathrm{P}$ e maior atividade da APase e da RNase na folha, no caule e na raiz.

4. A atividade das fosfatases decresceu com a idade das forrageiras.

5. Com o corte mais intenso, tanto Brachiaria decumbens quanto Panicum maximum cv. Tanzânia mostraram menor eficiência de utilização de $\mathrm{P}$, mesmo apresentando elevação nas atividades da APase e RNase 30 dias após o início dos cortes.

\section{LITERATURA CITADA}

ABEL, S. \& GLUND, K. Localization of RNA-degrading enzyme activity within vacuoles of tomato cells. Physiol. Plant., $66: 79-86,1986$

BALDWIN, J.C.; KARTHIKEYAN, A.S. \& RAGHOTHAMA, G. LEPS2, a phosphorus starvation-induced novel acid phosphatase from tomato. Plant Physiol., 125:728-737, 2001.

BARBER, S.A. Soil nutrient bioavailability: A mechanistic approach. 2.ed. New York, John Wiley, 1995.

BOSSE, D. \& KÖCK, M. Influence of phosphate starvation on phosphohydrolases during development of tomato seedlings. Plant Cell Environ., 21:325-332, 1998. 
BOZZO, G.G.; DUNN, E.L. \& PLAXTON, W.C. Differential synthesis of phosphate-starvation inducible purple acid phosphatase isozymes in tomato (Lycopersicon esculentum) suspension cells and seedlings. Plant Cell Environ., 29:303-313, 2006.

COMISSÃO DE FERTILIDADE DO SOLO DO ESTADO DE MINAS GERAIS - CFSEMG. Recomendações para o uso de corretivos e fertilizantes em Minas Gerais, $5^{\text {a }}$ aproximação. Viçosa, MG, 1999. 359p.

CHEN, C.R.; CONDRON, L.M.; SINAJ, S.; DAVIS, M.R.; SHERLOCK, R.R. \& FROSSARD, E. Effects of plant species on phosphorus availability in a range of grassland soils. Plant Soil, 256:115-130, 2003.

DONG, D.; PENG, X. \& YAN, X. Organic acid exudation induced by phosphorus deficiency and/or aluminum toxicity in two contrasting soybean genotypes. Physiol. Plant., 122:190-199, 2004.

DUFF, S.M.G.; SARATH, G. \& PLAXTON, W.C. The role of acid phosphatases in plant phosphorus metabolism. Physiol. Plant., 90:791-800, 1994.

EUCLIDES, R.F. Manual de utilização do programa SAEG Sistema para análises estatística e genéticas. Viçosa, MG, Universidade Federal de Viçosa, 1983. 59p.

GAHOONIA, T.S. \& NIELSEN, N.E. Phosphorus (P) uptake and growth of a root hairless barley mutant (bald root barley, brb) and wild type in low and high-P soils. Plant Cell Environ., 26:1759-1766, 2003.

GAUME, A.; MÄCHLER, F.; DE LEON, C.; NARRO, L. \& FROSSARD, E. Low P tolerance by maize (Zea mays L.) genotypes: Significance of root growth, and organic acids and acid phosphatase root exudation. Plant Soil, 228:253$264,2001$.

GEORGE, T.S.; TURNER. B.L.; GREGORY, P.J.; CADEMENUM, B.J. \& RICHARDSON, A.E. Depletion of organic phosphorus from Oxisols in relation to phosphatase activities in the rhizosphere. Eur. J. Soil Sci., 57:47-57, 2006.

HALSTED, M. \& LYNCH, J.P. Phosphorus responses of C3 and C4 species. J. Exper. Bot., 47:497-505, 1996.

LOWRY, O.H.; ROSEBROUGH, N.J.; FARR, A.L. \& RANDALL, R.J. Protein measurement with the folin phenol reagent. J. Biol. Chem., 193:265-275, 1951.

MURPHY, J. \& RILEY, J.P. A modified single solution method for determination of phosphate in natural waters. Anal. Chim. Acta, 27:31-36, 1962.

NANAMORI, M.; SHIMANO, T.; WASAKI, J.; YAMAMURA, T.; RAO, I.M. \& OSAKI, M. Low phosphorus tolerance mechanisms: phosphorus recycling and photosinthate partitioning in tropical forage grass, Brachiaria hybrid cultivar mulato compared with rice. Plant Cell Physiol., 45:460-469, 2004

NARANG, R.A.; BRUENE, A. \& ALTMANN, T. Analysis of phosphate acquisition efficiency in different arabidopsis accessions. Plant Physiol., 124:1786-1799, 2000.
NOVAIS, R.F. \& SMYTH, T.J. Fósforo em solo e planta em condições tropicais. Viçosa, MG, Universidade Federal de Viçosa, 1999. 399p.

NURUZZAMAN, M.; LAMBERS, H.; BOLLAND, M.D.A. \& VENEKLAAS, E.J. Distribution of carboxylates and acid phosphatase and depletion of different phosphorus fractions in the rhizosphere of a cereal and three grain legumes. Plant Soil, 281:109-120, 2006.

OZAWA, K.; OSAKI, M.; MATISUI, H.; HONMA, M. \& TADANO, T. Purification and properties of acid phosphatase secreted from lupin roots under phosphorusdeficiency conditions. Soil Sci. Plant Nutr., 41:461-469, 1995.

RAGHOTHAMA, K.G. Phosphate acquisition. Ann. Rev. Plant Physiol. Plant Molec. Biol., 50:665-693, 1999.

RAO, I.M.; AYARZA, M.A. \& GARCIA, R. Adaptive attributes of tropical forage species to acids soils. I. Differences in plant growth, nutrient acquisition and nutrient utilization among C4 grasses and C3 legumes. J. Plant Nutr., 18:2135-2155, 1995.

RICHARDSON, A.E.; GEORGE, T.S.; HENS, M. \& SIMPSON, R.J. Utilization of soil organic phosphorus by higher plants. In: TURNER, B.L.; FROSSARD, E. \& BALDWIN, D.S. eds. Organic phosphorus in the environment. Wallingford, CAB International, 2005. p.165-184.

RICHARDSON, A.E.; HADOBAS, P.A. \& HAYES, J.E. Acid phosphomonoesterase and phytase activities of wheat (Triticum aestivum L.) roots and utilization of organic phosphorus substrates by seedlings grown in sterile culture. Plant Cell Environ., 23:397-405, 2000.

RUFTY Jr., T.W.; ISRAEL, D.W.; VOLK, R.J.; QIU, J. \& TONGMIN, S.A. Phosphate regulation of nitrate assimilation in soybean. J. Exper. Bot., 44:879-891, 1993.

RUFTY Jr., T.W.; MACKOWN, C.T. \& ISRAEL, D.W. Phosphorus stress effects on assimilation of nitrate. Plant Physiol., 94:328-333, 1990.

SANTOS, H.Q.; FONSECA, D.M.; CANTARUTTI, R.B.; ALVAREZ V., V.H. \& NASCIMENTO JÚNIOR, D. Níveis críticos de fósforo no solo e na planta para gramíneas forrageiras tropicais em diferentes idades. R. Bras. Ci. Solo, 26:173-182, 2002.

SHEN, H.; YAN, X.; ZHAO, M.; ZHENG, S. \& WANG, X. Exudation of organic acids in common bean as related to mobilization of aluminum and iron-bond phosphates. Environ. Exper. Bot., 48:1-9, 2002.

SIDDIQI, M.Y. \& GLASS, A.D.M. Utilization index: A modified approach to the estimation and comparison of nutrient utilization efficiency in plants. J. Plant Nutr., 4:289-302, 1981.

VANCE, C.P; UHDE-STONE, C. \& ALLAN, D.L. Phosphorus acquisition and use: Critical adaptations by plants for securing a nonrenewable resource. New Phytol., 157:423447, 2003.

WATT, M. \& EVANS, J.R. Phosphorus acquisition from soil by lupin (Lupinus albus L.) and soybean (Glycine max L.), species with contrasting root development. Plant Soil, 248:271-283, 2003. 
WILSON, C.M. Plant nucleases. Ann. Rev. Plant Physiol., 26:187-208, 1975.

WISSUWA, M. How do plants achieve tolerance to phosphorus deficiency: Small causes with big effects. Plant Physiol., 133:1947-1958, 2003.

YADAV, R.S. \& TARAFDAR, J.C. Phytase and phosphatase producing fungi in arid and semi-arid soils and their efficiency in hydrolyzing different organic $\mathrm{P}$ compounds. Soil Biol. Biochem., 35:1-7, 2003.
YADAV, R.S. \& TARAFDAR, J.C. Influence of organic and inorganic phosphorus supply on the maximum secretion of acid phosphatase by plants. Biol. Fert. Soils, 34:140143, 2001.

YAN, X.; LIAO, H.; TRULL, M.C.; BEEBE, S.E. \& LYNCH, J.P. Induction of a major leaf acid phosphatase does not confer adaptation to low phosphorus availability in common bean. Plant Physiol., 125:1901-1911, 2001.

YUN, S.J.; \& KAEPPLER, S.M. Induction of maize acid phosphatase activities under phosphorus starvation. Plant Soil, 237:109-115, 2001. 